\title{
Asymmetric patterns of gap junctional communication in developing
} \section{chicken skin}

\author{
Florenci Serras $^{1, \star}$, Scott Fraser ${ }^{1, \dagger}$ and Cheng-Ming Chuong ${ }^{2}$ \\ 1Department of Physiology and Biophysics, University of California, Irvine, CA 92717 and Division of Biology, Beckman \\ Institute, California Institute of Technology, Pasadena, CA 91125, USA \\ 2Department of Pathology, University of Southern California, School of Medicine, HMR-204, 2011 Zonal Avenue, Los \\ Angeles CA 90033, USA \\ *Present address for correspondence: Departament de Genètica, Facultat de Biologia, Universitat de Barcelona, Diagonal 645, 08071 Barcelona, Spain \\ tPresent address: Division of Biology, Beckman Institute (139-74), California Institute of Technology, Pasadena, CA 91125, USA
}

\section{SUMMARY}

To study the pattern of gap junctional communication in chicken skin and feather development, we injected Lucifer Yellow into single cells and monitored the transfer of the fluorescent dye through gap junctions. Dye coupling is present between cells of the epithelium as well as between cells of the mesoderm. However, dye transfer did not occur equally in all directions and showed several consistent patterns and asymmetries, including: (1) no dye coupling between mesoderm and epithelium, (2) partial restriction of dye coupling at the feather bud/interbud boundary during early feather bud development, (3) preferential distribution of Lucifer Yellow along the anteroposterior axis of the feather placode and (4) absence of dye coupling in some epithelial cells. These results suggest the presence of preferential pathways of communication that may play a role in the patterning of chicken skin.

Key words: gap junction, intercellular communication, dye coupling, skin appendages, pattern formation, feather development

\section{INTRODUCTION}

During embryogenesis, structural and functional diversification of the ectoderm and mesoderm results in the development of specific tissues and organs. For example, lens placodes, otic placodes and feather placodes arise from the originally homogeneous ectodermal layer through the formation of a cell domain of placode epithelia, which is different from the neighboring cell domain of ectodermal epithelia. In previous reports, we have shown that cell adhesion molecules are localized in the developing skin in a periodical pattern that coincides with those cell domains (Chuong and Edelman, 1985a,b; Crossin et al., 1985; Richardson et al., 1987; Jiang and Chuong, 1992). It was hypothesized that N-CAM may be used to define cell domains undergoing tissue interactions, so that the cells within the cell domains will mutually interact and undergo the same developmental fate (Chuong et al., 1993). Computer simulations and perturbation experiments suggest that placode formation and development must be accompanied by some dialogue between the cells (Meinhardt, 1984; Gallin et al., 1986). One possible mechanism for placode formation is through sharing of small signal molecules via gap junctions. Interestingly, experiments in which N-CAM function in cultured neuroepithelium was blocked with antibodies resulted in the inhibition of gap junctional commu- nication (Keane et al., 1988). Thus, it is possible that the cell domains of the skin defined with cell adhesion molecules generate gap junctional communication domains.

Gap junctions are plasma membrane specializations that form a channel permeable to small molecules and ions between the interiors of neighboring cells. Intercellular communication by means of gap junctions has been shown in several embryos and embryonic tissues at the time of their patterning. Exchange of second messengers via gap junctions has been demonstrated (Lawrence et al., 1978; Saez et al., 1989); similar exchanges could explain signal transduction mechanisms that take place in a variety of cell types (Brehm et al., 1989; Cornell-Bell et al., 1990). The potential for gap junctions to mediate intercellular signalling is largely responsible for the commonly held opinion that gap junctions play a role in the exchange of information between embryonic cells (reviewed in Guthrie and Gilula, 1989). Experimental perturbations with gap junction selective antibodies suggest that this pathway may be involved in several interactions (Warner et al., 1984; Fraser et al., 1987; Lee et al., 1987; Allen et al., 1990) but almost certainly is not in others (Warner and Gurdon, 1987).

Skin morphogenesis offers an excellent model for further analysis of tissue patterning because of the process in which the distinct skin appendages are formed. In feather development, induction of the ectoderm leads to the formation 
of two domains with different developmental fates: the hexagonally arranged placode domains that will form the feathers and the interbud domains that will form the apterium region. During subsequent development, mesodermal cells condense directly beneath the placode epithelium to form a feather bud. Later the feather bud epithelium, but not the interbud epithelium, undergoes rapid cell proliferation and grows out of the flat epithelium. In addition to the distinct bud and interbud ectodermal domains described above, feather buds also display a morphological anterior-posterior polarity (Fig. 1), which becomes more clear in the adult feather with the rachis being at the site where the anterior feather bud is originated. Placing a retinoic acid-soaked bead on a skin explant at early stages when no morphological anterior-posterior polarity is apparent can alter axial orientation of feather buds that later grow out (Chuong et al., 1992). Therefore, the anterior-posterior orientation of the feather bud is determined before the morphological cues. Interestingly, a graded distribution of molecules along the anteriorposterior (A-P) axis of the feather bud has been observed. N-CAM, tenascin and the homeoproteins XlHbox 1 (a Hox 3.3 homologue) and Hox 4.2 are enriched in the anterior side (Chuong and Edelman, 1985a; Chuong et al., 1990; Jiang and Chuong, 1992), whereas fibronectin and collagen type III are enriched in the posterior bud (Mauger et al., 1982; Chuong et al., 1991). If gap junctional communication is part of the physiological mechanism involved in the patterning of chick skin, the pattern of communication might parallel the cell domains observed by morphological criteria and molecular markers. This would predict asymmetrical patterns of gap junctional communication, particularly near the border that separates the cell domains. Embryonic chicken skin, with its regular arrays of feather primordia offers an excellent opportunity to test this hypothesis. A potential role of gap junctions in skin patterning is somewhat supported by studies done in mammalian skin using dye injection, which show compartmentalization of gap junctional communication of the dermis, epidermis and hair follicle (Kam et al., 1986; Kam and Hodgins, 1992), and spatiotemporal patterns of expression of different connexins (Risek et al., 1992).

To explore the pattern of functional gap junctional communication in the cell domains during chick skin development, we performed single cell injections of the fluorescent dye Lucifer Yellow during feather placode and bud development. Lucifer Yellow is known to pass through gap junctions and is indicative of functional gap junctions (dyecoupling assay). Our aim is to identify whether cells in the developing chicken skin are selectively dye coupled and whether there is any preferential distribution of Lucifer Yellow that can parallel the morphological and molecular domains.

\section{MATERIALS AND METHODS}

\section{Skin explants}

Fertilized White Leghorn chick eggs (K and R Farm, Westminster, $\mathrm{CA}$ ) were kept in an incubator at $37.5^{\circ} \mathrm{C}$ in a humidified atmosphere. Embryos were staged according to the criteria of Hamburger and Hamilton (1951). Feather buds over different parts of body surface develop at different time schedules. The first ones begin to develop on the dorsal surface of the embryo at the stage 31. In this work, we used only cultures of dorsal skin and analyzed buds near the dorsal midline.

At set time intervals, the eggs were washed with $70 \%$ ethanol and the embryos were removed and submerged in media (Dulbeccos modified Eagles Medium (DMEM) plus $25 \mathrm{mM}$ Hepes, $\mathrm{pH}$ 7.4). A rectangular piece of dorsal skin (about 5-10 mm long and $5 \mathrm{~mm}$ wide) was dissected with microscissors. The orientation of the skin explant was marked by a small cut at the anterior edge. The skin was transferred with the epithelium facing up to a dish filled with culture medium, containing a polycarbonate membrane filter (Poretics; $5 \mu \mathrm{m}$ pore) at the bottom. The culture medium was aspirated gently until only a thin layer of culture medium covered the filter and skin. This preparation was mounted on the stage of a Zeiss UEM epifluorescence microscope, where the microinjections were conducted.

\section{Gap junctional communication}

Intercellular communication mediated by gap junctions was assessed by intracellular microinjection of the fluorescent tracer Lucifer Yellow CH (Stewart, 1978) and subsequently monitoring the passage from the injected cell to neighbouring cells. The term dye coupling is used when small dyes are transferred from cell to cell. Microelectrodes were made of thin wall aluminosilicate capillaries (A-M systems) pulled in a microelectrode puller (Sutter Instruments). Microelectrodes were back-filled with 3\% Lucifer Yellow CH (Molecular Probes), mounted on a micromanipulator and connected to a Neurodata Instruments amplifier with a bridge circuit. The reference electrode was inserted into a block of $2 \%$ agar in culture medium, which was placed on top of the polycarbonate membrane. Cells were impaled using negative capacitance 'ringing' of the microelectrode. Membrane potentials were recorded to confirm a successful impalement and to monitor the conditions of the impaled cells. Lucifer Yellow was iontophoresed into the cells for 30-120 seconds, with hyperpolarizing current pulses of $4 \mathrm{nA}$ amplitude and $200 \mathrm{~ms}$ duration supplied by the current passing microelectrode amplifier. The membrane potential was monitored continuously with a digital storage oscilloscope (Gould). The passage of dye to injected cells was monitored briefly during the injection with the epifluorescence microscope. Electronic shutters on phase and fluorescence paths were used to minimize the exposure of the cells to wavelengths that could cause phototoxic effects on the dye-filled cells.

After injection, dye-filled cells were photographed in vivo on Kodak Ektachrome 400 ASA film. Successfully injected tissues were fixed in $3.7 \%$ formaldehyde (Fisher) in $0.1 \mathrm{M}$ phosphate buffer at $4{ }^{\circ} \mathrm{C}$, washed and mounted on glass slides using $70 \%$ glycerol, $5 \% \mathrm{~N}$-propyl gallate in $30 \mathrm{mM}$ Tris $\mathrm{pH} 9$.

\section{Confocal laser scanning microscope (CLSM)}

Specimens were examined with a Bio-Rad MRC-600 confocal laser scanning microscope, mounted on a Zeiss Axiovert microscope. Series of optical sections were made through the dyeinjected skin explants. For each specimen, both fluorescence and phase-contrast images were collected, stored and displayed by means of the BioRad CM software package. Analysis of the optical sectioning along the z-axis made possible the determination of the position and cell layer of the Lucifer Yellow-labelled cells.

\section{Nucleus staining}

When dead cells in living skin explants were to be identified, the cultured explants were stained with propidium iodide $(5 \mathrm{mg} / \mathrm{ml}$ stock) diluted 1:1000 in culture medium for 3 minutes, and washed in culture medium. When specimens were fixed in formaldehyde and then stained with propidium iodide (diluted 1:1000 in $0.1 \mathrm{M}$ 
phosphate buffer $\mathrm{pH} 7.4$ ), all nuclei of the skin were labelled (not shown).

Lucifer Yellow-injected specimens were fixed in $3.7 \%$ formaldehyde, washed in $0.1 \mathrm{M}$ phosphate buffer and stained with Hoechst $33258(10 \mathrm{mg} / \mathrm{ml}$ stock) diluted (1:2000) in $0.1 \mathrm{M}$ phosphate buffer $\mathrm{pH} 7.4$ for 30 seconds. After staining, specimens were washed in $0.1 \mathrm{M}$ phosphate buffer and mounted. After staining the nuclei, specimens were examined with a Zeiss Axiophot microscope. The fixation or mounting did not change the overall pattern. Photographs were taken on Kodak Ektachrome 400 ASA.

All images taken with the fluorescence microscope were scanned with a Color Imaging Systems (Barneyscan Corporation) scanner. As with the CLSM images, these images were processed using Adobe Photoshop on a Macintosh IIFX. Processed images show raw data and were printed using a Nikon CP3000 thermal dye sublimation printer.

\section{RESULTS}

During the early development of the skin, formation of placode and mesodermal condensations begins as a single row along the dorsal midline of the stage 31 embryo. Additional rows then appear successively on either side of the initial dorsal row. Feather buds, which consist of a protruding epithelium and a mesodermal core, gradually form (around stage 33) from the placodes (Fig. 1). Further differentiation and organization of the feather bud mesoderm and epithelium will form the feather. In this study, we have focused on embryonic chicken skin from stages 30 to 36 . Embryonic chicken skin explants were dissected and mounted on a filter for microinjection in Hepes-buffered DMEM. All experiments were finished within 1 hour after dissection. The patterns of dye coupling were analyzed with epi-fluorescence microscope and confocal laser scanning microscope (CLSM).

Because of the opacity of the skin, it is not possible to identify precisely what cell layer has been impaled under the microscope of the microinjection set-up. However, two different criteria were used in this work to localize and identify the injected cell and other dye-coupled cells. First, a voltage deflection was always recorded in the oscilloscope when a cell was impaled. A unstable small voltage deflection of about -1 or $-5 \mathrm{mV}$ was observed when the microelectrode went through a cell of the outer monolayer (the periderm) towards the epithelium. After further penetration, a membrane potential ranging from $-10 \mathrm{mV}$ to $-35 \mathrm{mV}$ was detected. Since at this stage the periderm is a monolayer, the second voltage deflection can be interpreted as a successful impalement into an epithelial cell. Second, injections in the inner epithelium were distinguished from injections in the outer periderm by subsequent observations in the epifluorescence and the confocal laser scanning microscopes. Examination of the specimens permitted injections into the extracellular spaces to be discerned from intracellular injections and discarded. Lucifer Yellow tends to be localized in the nuclei when injected intracellularly (confirmed by nuclear staining with Hoechst 33258). In contrast, Lucifer Yellow shows a dispersed transfer when injected extracellularly making such samples simple to recognize.

\section{Dye coupling in the placode epithelium}

When injected into single cells of the epithelium at the early placode stage, Lucifer Yellow was found to travel from the injected cell to the surrounding cells. Preparations visualized during and after the injection showed rapid and extensive dye transfer to neighboring cells. For example, Fig. 2 shows the extent of dye transfer 1, 5 and 20 minutes after injection. Because Lucifer Yellow tends to bind to the nuclei, labelled cells can be distinguished by the localization of most of the intercellular dye in the nuclei, which is surrounded by the less bright cytoplasm (Fig. 2A). One minute after injection, Lucifer Yellow had passed from the injected cell to more than 100 other cells (Fig. 2A,B). In the center of the area of labelled cells, highly concentrated dye is found in a cluster of 25 to 30 cells corresponding to the first tiers of cells around the injected one. With subsequent in vivo observations of the same preparation, the dye transferred from the highly labelled cell cluster to increase the
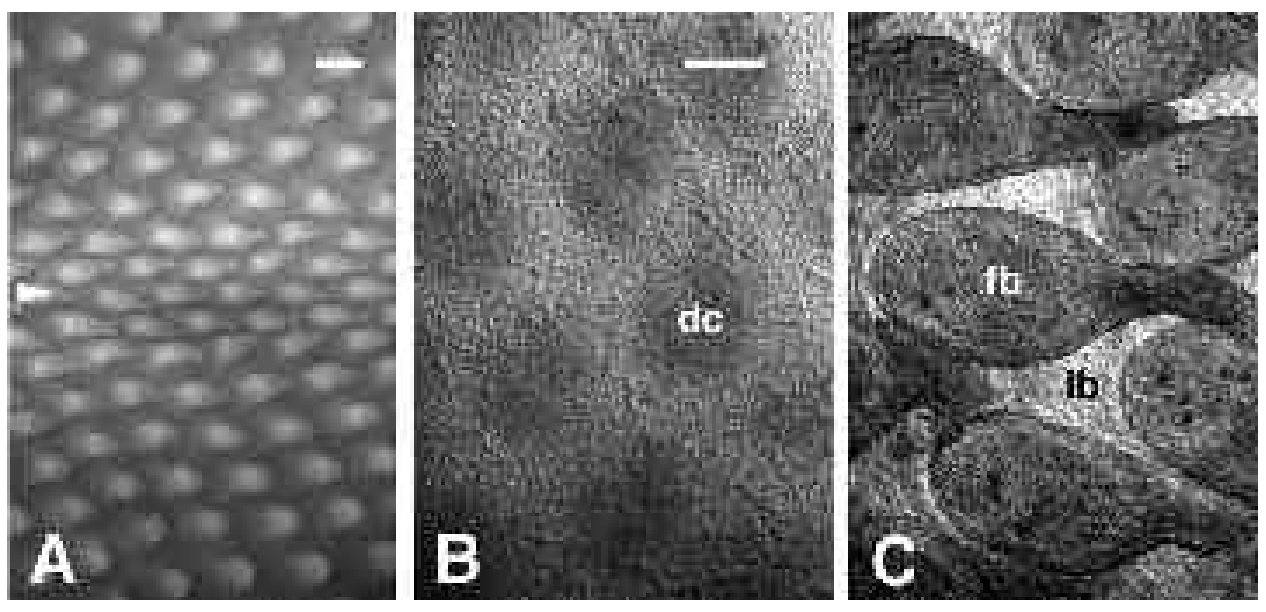

Fig. 1. Development of cultured chicken embryo skin explants. (A) Rows of feather buds forming on a stage 35 skin explant shows the regular hexagonal pattern. Arrowhead points to the dorsal midline along which the first developing row of feather buds is formed. Those feather buds located peripheral to the dorsal midline are less developed than those near the midline. (B) CLSM image of the skin explant of stage 32 showing the regularly spaced dermal condensations (dc). (C) CLSM image of feather buds after an explant like that in B was cultured for 4 days. Note that, in this period, the dermal condensations have grown into elongated feather buds (fb) protruding out of the skin surface; $\mathrm{ib}$, interbud domain. All panels are oriented with the anterior side of the feather bud to the left and posterior side to the right. Bar, $200 \mu \mathrm{m}$ for panel $\mathrm{A}$ and $100 \mu \mathrm{m}$ for panels B and C. 

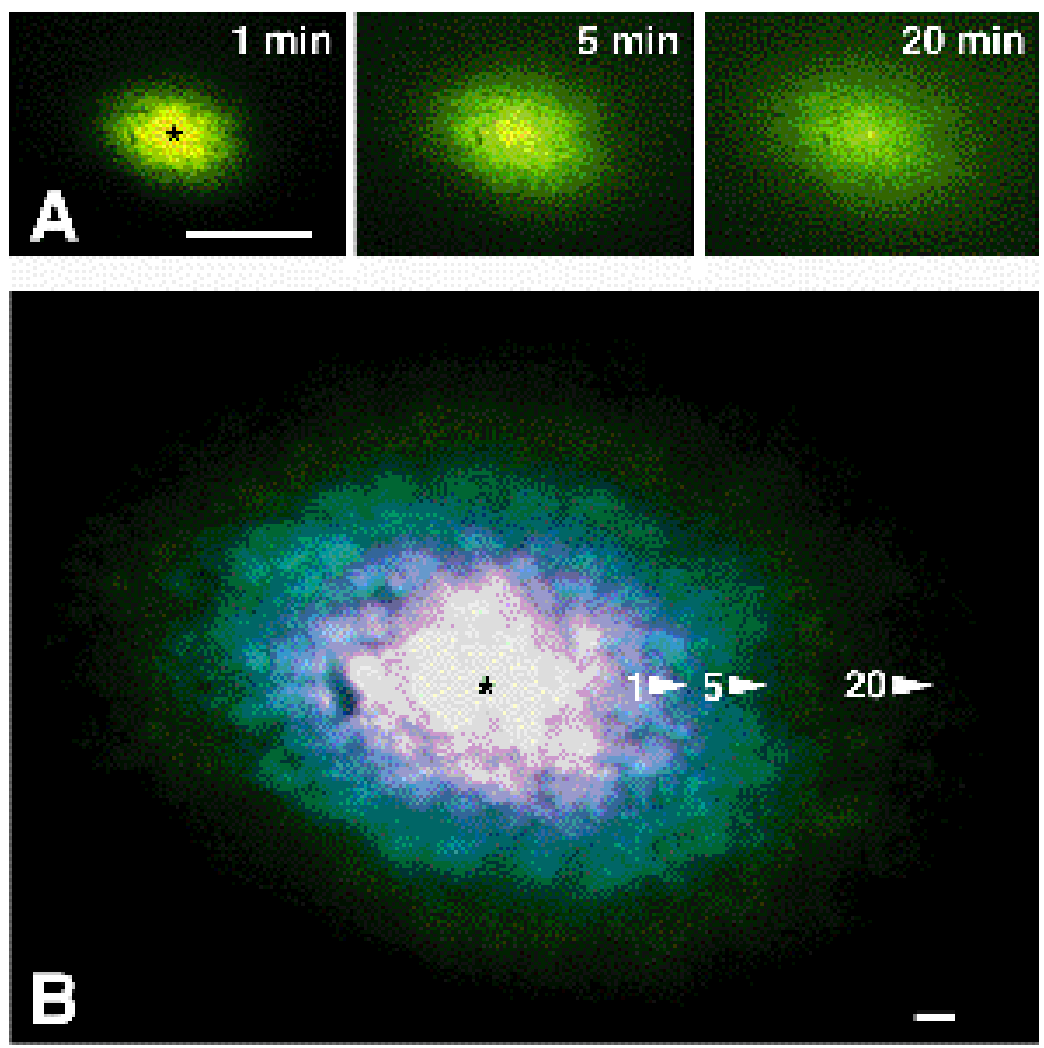

Fig. 2. Epifluorescent images taken at different time after Lucifer Yellow was injected into an epithelial cell within a placode. Stage 33 chicken skin. (A) Lucifer Yellow was injected into a single cell (asterisk) and fluorescent images photographed 1, 5 and 20 minutes after injection. (B) Superimposition of the three images in A (pseudocolored) to show the extension of dye coupling as a function of time. The white area on the center corresponds to the cluster of highly labelled cells surrounding the injected cell (asterisk); both the white and pink-purple area correspond to the cells filled with dye 1 minute after injection; blue area corresponds to the cells to which dye was transferred during the following 4 minutes; dark green corresponds to cells filled with dye during the following 15 minutes. Arrowheads point to the limit of dye coupling after 1, 5 and 20 minutes after injection. Bar, 100 $\mu \mathrm{m}$ for $\mathrm{A}$ and $10 \mu \mathrm{m}$ for B. total area of labelled cells (Fig. 2A,B). After microinjection, all specimens were observed every 5 minutes for about 30 minutes. After 20 to 25 minutes, no further transfer was detected in either direction. In this preparation, as in others, Lucifer Yellow may become non-diffusible over time because of binding to the nuclei or cytoplasmic constituents. Dye coupling was not strictly restricted to the placode epithelium. Coupling occurred between placode and interplacode epithelium.

The cell layer to which the labelled cells belong could not be distinguished in vivo with certainty under a conventional epifluorescence microscope. Therefore, these specimens were analyzed with a CLSM, either in vivo, after fixation, or both. The images showed a layer of Lucifer Yellowlabelled epithelial cells directly beneath a brightly labelled peridermal cell, suggesting that the epithelial cells were impaled successfully after the electrode passed through the outer peridermal cells. The number of labelled cells after Lucifer Yellow injection was counted from epifluorescence photographs or from CLSM prints. When Lucifer Yellow was injected into a peridermal cell (Table 1), transfer was found only in a few other peridermal cells (less than 10 cells labelled). In contrast, when a cell of the epithelium was injected, dye coupling was much more extensive. From 29 dye-injections in the epithelial cells, 27 showed transfer of Lucifer Yellow to more than 10 cells (93\%, Table 1); eight cases $(28 \%)$ showed dye coupling of more than 200 cells. No transfer from those dye-coupled epithelial cells to the adjacent periderm was found.

To determine if there is dye transfer between the epithelium and the mesodermal cells, serial optical sections were made in steps from 1.5 to $3.5 \mu \mathrm{m}$ in the CLSM (Fig. 3). Analysis of these sections revealed no dye in the immediately subadjacent mesoderm. This clear absence of dye in the mesoderm (Fig. 3D) suggests there is no dye coupling between the epithelial cells and the underlaying mesodermal cells.

In many of the cases, the pattern of dye-coupled cells in

Table 1. Incidence of results after intracellular injection of Lucifer Yellow in developing chicken skin

\begin{tabular}{|c|c|c|c|c|c|}
\hline \multirow[b]{2}{*}{ Site of injection: } & \multirow[b]{2}{*}{ Stage* } & \multicolumn{4}{|c|}{ Number of dye-coupled cells } \\
\hline & & $\begin{array}{l}<10 \\
\%(\mathrm{n})\end{array}$ & $\begin{array}{c}10-100 \\
\%(\mathrm{n})\end{array}$ & $\begin{array}{l}>100 \\
\%(\mathrm{n})\end{array}$ & $\begin{array}{c}\text { total } \\
\mathrm{n}\end{array}$ \\
\hline Placode epithelium & $30-32$ & $7(2)$ & $52(15)$ & $41(12)$ & 29 \\
\hline Periderm & $30-32$ & $100(4)$ & $0(0)$ & $0(0)$ & 4 \\
\hline Interbud epithelium & $33-36$ & $21(4)$ & $53(10)$ & $26(5)$ & 19 \\
\hline Feather bud epithelium & $33-36$ & $30(6)$ & $65(13)$ & $5(1)$ & 20 \\
\hline Feather bud mesoderm & $33-36$ & $7(1)$ & $79(11)$ & $14(2)$ & 14 \\
\hline
\end{tabular}



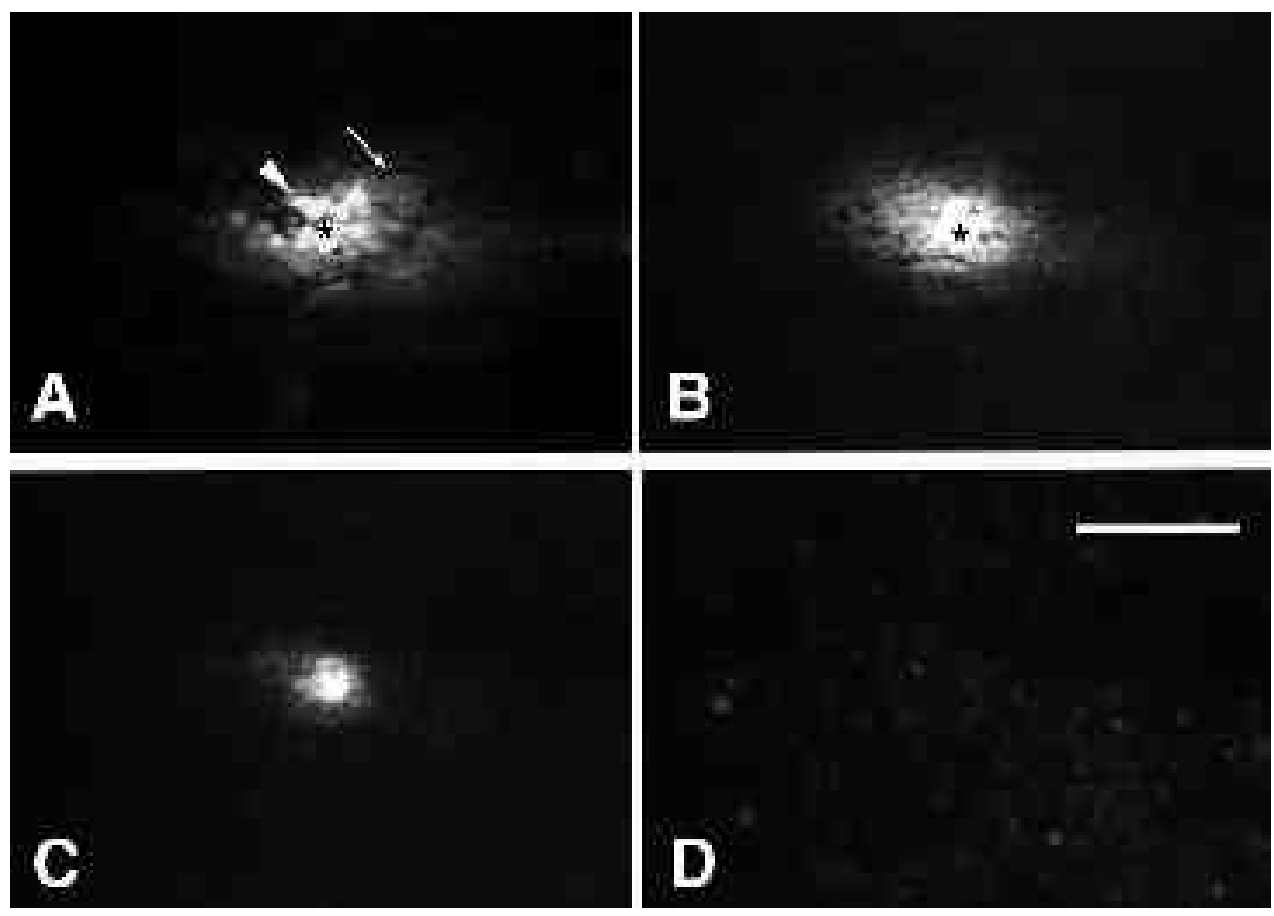

Fig. 3. CLSM optical sections show the dye distribution in the placode after Lucifer Yellow was injected into a placode epithelial cell. Stage 33 chicken skin. (A) Close to the outer surface. Both peridermal (large) and epithelial (small) cells are labelled; arrowhead points to one peridermal cell; arrow points to epithelial cells. (B) 7 $\mu \mathrm{m}$ below, dye coupling can be seen in the placode epithelial cells. (C) $10.5 \mu \mathrm{m}$ below the image of panel A, some labelled epithelial cells are still visible because the placode epithelium is thicker. (D) 27.5 $\mu \mathrm{m}$ below the image of panel $\mathrm{A}$; this level is in the mesodermal area and the mesodermal cells show no traces of Lucifer Yellow. Bar, $100 \mu \mathrm{m}$.

early placode epithelium was asymmetrical. In the remaining cases, the dye was spread either radially symmetrical or irregularly to other cells, or to too few cells to distinguish any pattern. In the asymmetrical cases (15 out of 29), Lucifer Yellow was found to spread in an elongated pattern (Fig. 4). To study the extend of the dye-coupling asymmetry, we measured the number of cells filled with dye along the major and minor axis of the dye-labelled area (the injected cell was at the cross point between both axes). These measurements (Table 2) showed that the ratio between the values of the major and minor axis is almost
$2: 1$. The mean of the labelled cells was $24.46 \pm 2.01 \quad(n=15$, s.e.m.) for the major axis and $13.2 \pm 1.06(n=15$, s.e.m.) for the minor axis. In almost all cases (13 of 15), the major axis of the dye-coupling area coincides with the anterior posterior (A-P) axis of the embryo (Fig. 4). At the stages studied (stages 30 and 31), no clear morphological A-P asymmetries were distinguished in the individual placodes.

Analysis of the distribution of Lucifer Yellow dye showed that it did not transfer uniformly from the microinjected cell to all the neighboring cells. Apparently random unlabelled spots can be seen within the dye-coupled area
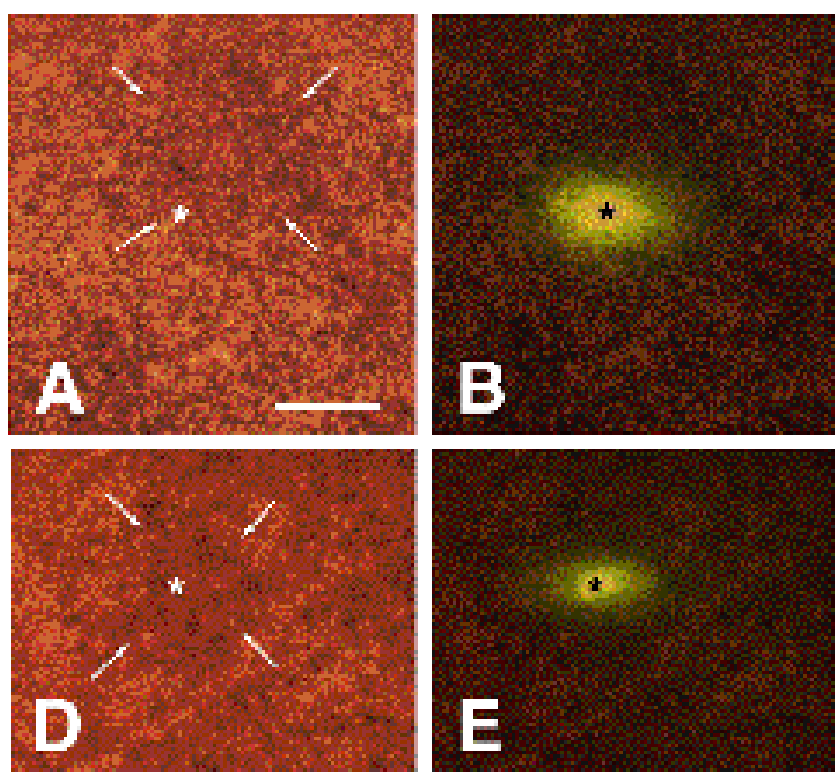
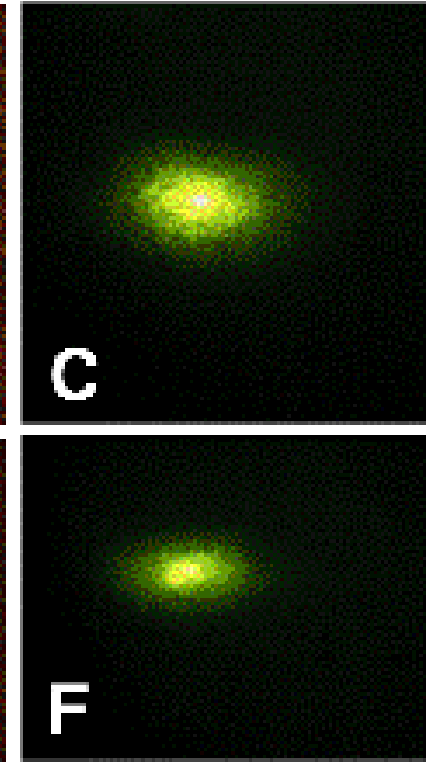

Fig. 4. Asymmetric patterns of dye coupling in placodes. Phase-contrast images are shown in the left, fluorescence images are shown in the right, and combined phase and fluorescence images are shown in the middle to facilitate the comparison of dye distribution and morphology. Stage 32 skin. (A-C) An epithelial cell on the edge of a placode was injected. (D-F) An epithelial cell localized at the center of the placode was injected. The feather germ, which includes placode and dermal condensations, is still forming and the border can barely be

seen (arrows). A-P axis of the feather germ is from left to right. Note that, in both cases, there is preferential dye coupling along the anterior-posterior axis. Asterisk: injected cell. Bar, $100 \mu \mathrm{m}$. 

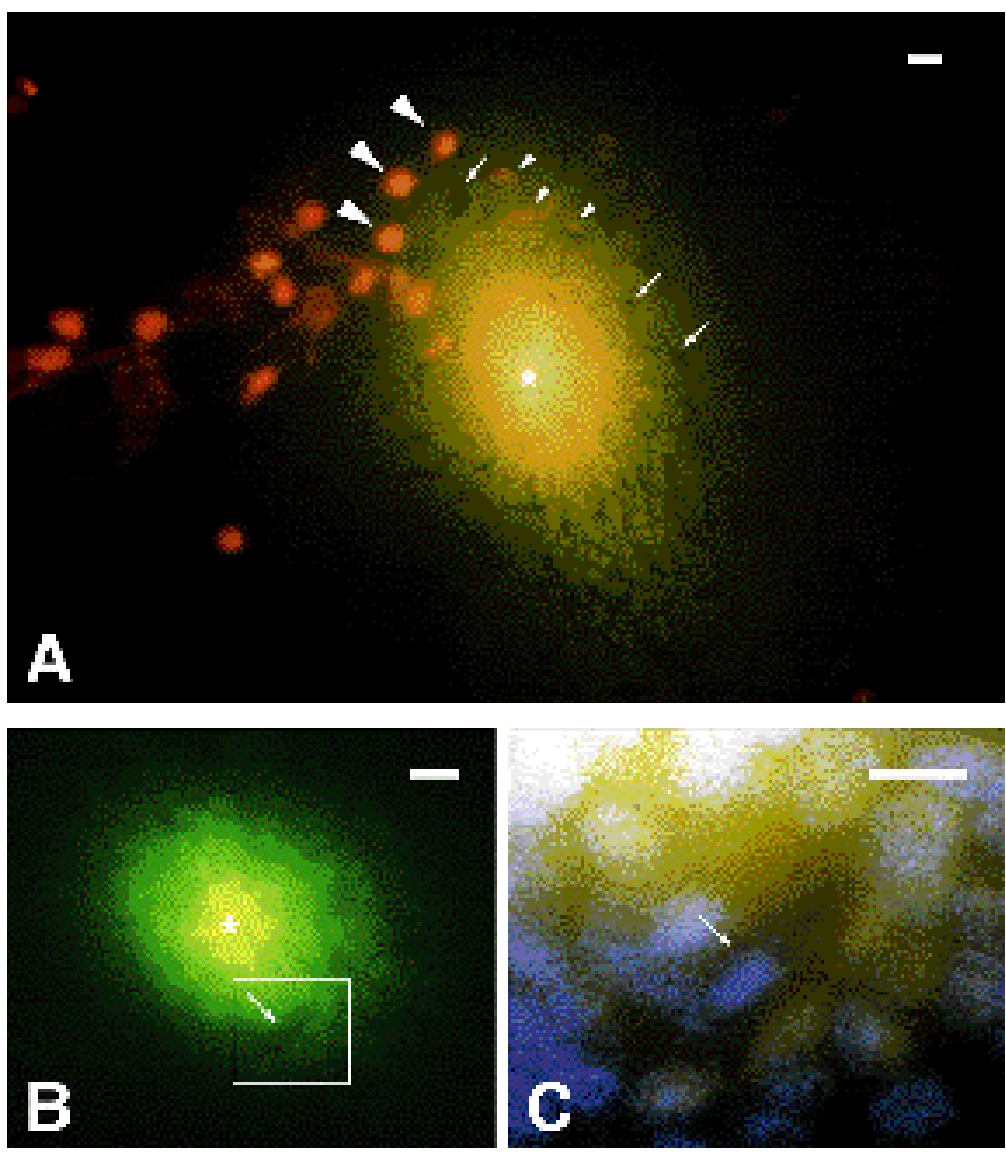

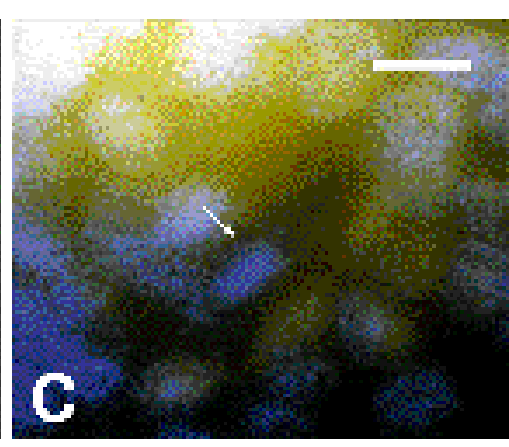

Fig. 5. Uncoupled cells within the dye-coupled area (arrows). (A) Combined image of an injection of Lucifer Yellow (yellow) and staining with propidium iodide (red-orange) in vivo. Arrows: some unlabelled cells. Large arrowheads: point to some propidium iodide-labelled peridermal cells; small arrowheads: point to propidium iodidelabelled epithelial cells. Asterisk, injected cell. (B) Specimen after fixation. Arrow points to the unlabelled spot. Inset corresponds to $\mathrm{C}$.

(C) Combined Hoechst labelling of the nuclei (purple) and Lucifer yellow (yellow and white) image. Note that a nuclei in the unlabelled spot is visible (arrow). Scale bars: A and B, $20 \mu \mathrm{m} ; \mathrm{C}, 10$ $\mu \mathrm{m}$.
(Fig. 5; dark spots also can be seen in Figs 3B, 4C). Analysis with CLSM showed that these unlabelled cells were at the level of placode epithelium, not in the periderm or mesoderm. To determine whether there were cells within these unlabelled spots or whether they were acellular, we labelled Lucifer Yellow-injected skin explants with the dye Hoechst 33258. The Hoechst dye

Table 2. Asymmetry in the dye-coupling pattern of the early placode stages

\begin{tabular}{ccc}
\hline $\begin{array}{c}\text { Dye-labelled } \\
\text { cells along } \\
\text { major axis }\end{array}$ & $\begin{array}{c}\text { Dye-labelled } \\
\text { cells along } \\
\text { minor axis }\end{array}$ & $\begin{array}{c}\text { Ratio between } \\
\text { minor and major } \\
\text { axis }\end{array}$ \\
\hline 22 & 15 & 0.68 \\
$29 *$ & 16 & 0.55 \\
$21 * *$ & 11 & 0.52 \\
22 & 9 & 0.40 \\
40 & 19 & 0.47 \\
29 & 14 & 0.48 \\
18 & 7 & 0.38 \\
19 & 13 & 0.68 \\
19 & 10 & 0.52 \\
19 & 12 & 0.63 \\
25 & 15 & 0.60 \\
43 & 23 & 0.53 \\
24 & 14 & 0.58 \\
19 & 9 & 0.47 \\
18 & 11 & 0.61 \\
$*$ Corresponds to the example shown in Fig. $4 \mathrm{~A}-\mathrm{C}$. & \\
$* *$ Corresponds to the example shown in Fig. 4D-F. & \\
24.46 & $13.2 \pm 1.06$ & \\
\hline
\end{tabular}

showed that there were 1 or 2 nuclei in each of the unlabelled spots (Fig. 5B,C). It is possible that these dark spots represented injured cells with reduced coupling that resulted from tissue manipulation. To test this possibility, we used in vivo propidium iodide staining, which selectively labels dead cells or cells in which the membrane has been permeabilized by injury. In Lucifer Yellow-injected and propidium-stained specimens, propidium iodidestained cells were scattered over the surface of the periderm (Fig. 5A). Occasionally, the epithelial cells that had been impaled with the Lucifer Yellow microelectrode were also labelled. However, most of the placode epithelium, including the unlabelled spots were not stained with propidium iodide (Fig. 5A, arrows). Thus the unlabelled spots represent intercalated cells that are poorly or not coupled to the surrounding cells.

\section{Dye coupling in the feather bud and interbud epithelia}

At the feather bud stage, we observed an asymmetry in the pattern of dye coupling: the feather bud epithelium and the interbud epithelium appear to be separated into two domains by a communication boundary. When Lucifer Yellow was injected into a cell in the middle of the interbud domain, the dye transferred towards other interbud epithelial cells, with some A-P dye-coupling preference (Fig. 6A-C). In contrast, when an interbud cell near the feather bud was injected, the dye transferred towards other cells of the interbud domain resulting in an asymmetrical pattern of dye coupling (Fig. 

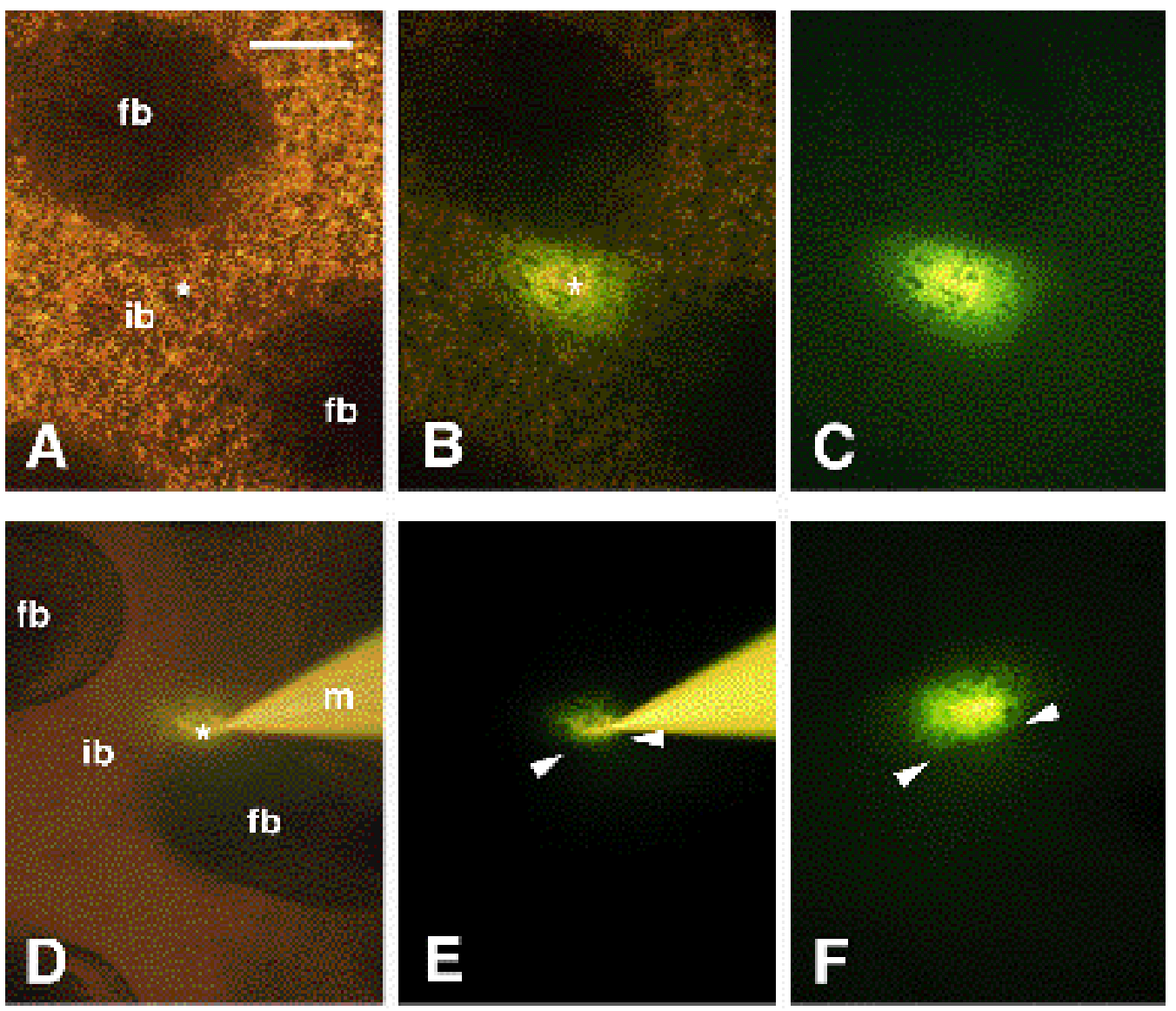

Fig. 6. Asymmetrical pattern of dye coupling at the border between the feather bud (fb) and interbud (ib) domains, after injection of an interbud epithelial cell. Stage 34 chicken skin. (A-C) Injection of a cell between feather buds. Note that dye transfer occurs around the injected cell (asterisk). Dye tends to transfer AP. A-P axis is from left to right. (D-F) Injection of a cell in the interbud region but close to the anterior lateral margin of a bud. (D) Combined phase and fluorescence and (E) fluorescence; both with the Lucifer Yellow filled microelectrode $(\mathrm{m})$ inserted into injected cell (asterisk). Arrowheads point to the border between the interbud and bud epithelium. Note that when cells in the middle of the interbud region were injected, dye was more evenly distributed (C). When cells near the bud border was injected, the dye transfers more extensively towards other interbud cells but did not transfer into the feather bud epithelial cells. D and E are pictures taken during the injection of Lucifer Yellow; F is the same preparation but taken 15 minutes later. Bar, 100 $\mu \mathrm{m}$.

6D-F). If the same preparations were observed multiple times, eventually dye coupling was found across the budinterbud border in only 4 of the 19 cases studied. Overall, the dye coupling within interbud epithelia was extensive (Fig. 6A-C), with coupling to over 10 cells in $79 \%$ of the successfully injected specimens and to over 100 cells in $26 \%$ of the cases ( $n=19$; Table 1$)$. Intercalated communicationincompetent cells (dark spots) also were found in the interbud epithelia at this stage.

When the feather bud epithelial cells were injected, the dye transfers to other bud epithelial cells but not to interbud epithelial cells. Fig. 7 shows the result of injections into a cell of the most anterior part of the bud epithelium. The dye travelled preferentially from the injected cell to other epithelial-bud cells, even though the interbud cells were closer. Subsequent in vivo observations of the injected feather bud preparations showed further transfer of Lucifer Yellow towards other bud cells rather than to the interbud. Only when the site of injection was very close to the interbud were some interbud epithelial cells labelled. Transfer across the border was detected in 3 out of 20 cases. The extension of the transfer across the border, independently of whether the bud or interbud was injected, does not exceed two rows of cells along the border.

The communication border that separates the bud from the interbud was found in early feather bud stages of the skin as shown in the two examples of the Fig. 7A-F. In later stages of the feather bud development, the interbud-bud communication border is still found after injections in the anterior end of the bud (Fig. 7G-J).

\section{Dye coupling in the feather bud mesoderm}

Epithelium-mesodermal interaction is of critical importance to the development of skin appendages. To determine whether there is gap junction communication between epithelium and mesoderm at this stage, we analyzed specimens in which the feather bud epithelium was injected, with optical sections on a CLSM. A series of optical sections at $4 \mu \mathrm{m}$ intervals is shown in Fig. 8. On the bud surface, the dye can be seen to transfer in a plane (Fig. 8A, panel 1). When the same preparation is focussed into the feather bud, where the border between mesoderm and epithelium can be seen clearly, the staining shows a peripheral pattern of coupled cells (Fig. 8, panels 2-9). Those peripheral coupled cells correspond to the epithelium of the bud. This result clearly indicated that there is no dye transfer from the epithelial cells to the mesoderm at this stage.

To test whether there is dye transfer from mesodermal cells to epithelial cells, we injected mesodermal cells of the feather bud between stages 34 and 36. To inject the meso- 

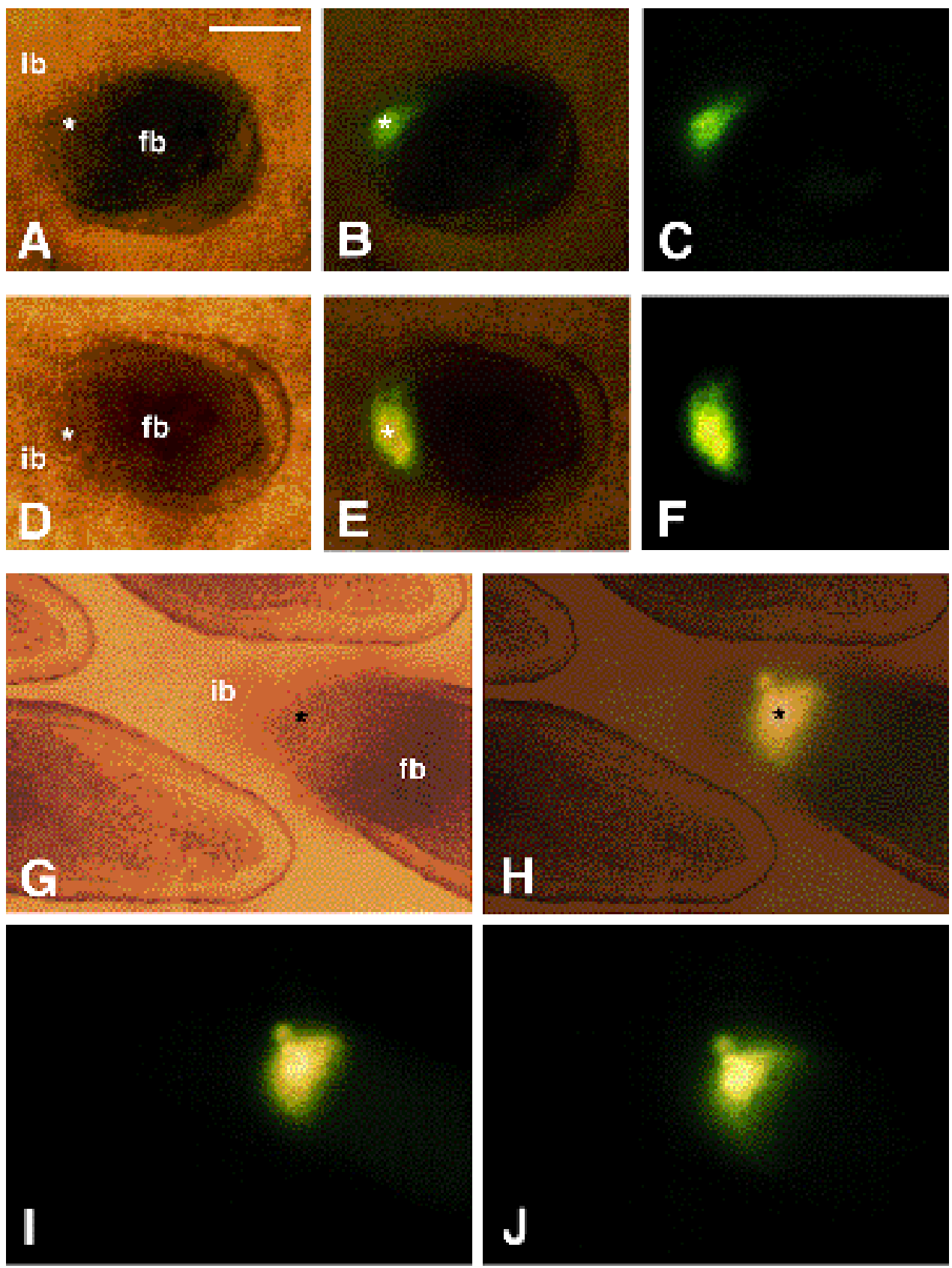

Fig. 7. Asymmetrical pattern of dye coupling at the border between the feather bud ( $\mathrm{fb}$ ) and interbud (ib) domains after injection of a feather bud epithelial cell. (A-C) Stage 34 skin explant injected into a cell of the anterior lower margin of the bud. (D-F) Stage 34 skin explant injected into a cell of the anterior upper margin of the bud. (G-J) Stage 36. Injection of a cell in the anterior margin of the bud. Superimposed image $(\mathrm{H})$ and fluorescence $(\mathrm{I})$ were taken after injection; image (J) was taken 15 minutes after injection. Note that, in all these cases, the dye preferentially transferred towards the bud epithelial cells but did not cross the border to transfer to interbud epithelial cells. Bar, $100 \mu \mathrm{m}$. dermal cells, the microelectrode was brought through the periderm and epithelium (while monitoring the small voltage deflections resulting from crossing the living cells) until a stable membrane potential was reached in the mesoderm (from -10 to $40 \mathrm{mV}$ ). Attempts to inject single cells of the mesoderm often resulted in injections into the extracellular space possibly because the cells of the mesoderm are smaller (less than $10 \mu \mathrm{m}$ ) than the epithelial cells. Injections were assumed to be extracellular if: (1) no voltage deflection below $-5 \mathrm{mV}$ was found; (2) a voltage deflection similar to the one of a good impalement was detected, but only for a fraction of a second, then returning to the potential of the medium; (3) after fixation and mounting the specimen, no Lucifer Yellow was found in the cells or (4) Lucifer Yellow stained the periphery of the cells and not the nuclei. Injections in the extracellular space were discarded.

Successfully injected mesodermal cells were fixed and mounted for CLSM analysis ( $n=14$; Table 1). Confocal examinations of the Lucifer Yellow-injected specimens show that the mesoderm cells are well coupled (Fig. 9). Again, a dye-coupling barrier could be observed at the border between the mesoderm and epithelium when a mesodermal cell close to epithelium was injected. The dye spread to other neighboring mesodermal cells but not to the overlaying epithelial cells (Fig. 9). Together with the injections performed on the epithelial cells, the data suggest that feather bud epithelium and mesoderm belong to different gap junction communication domains at the stages examined. 

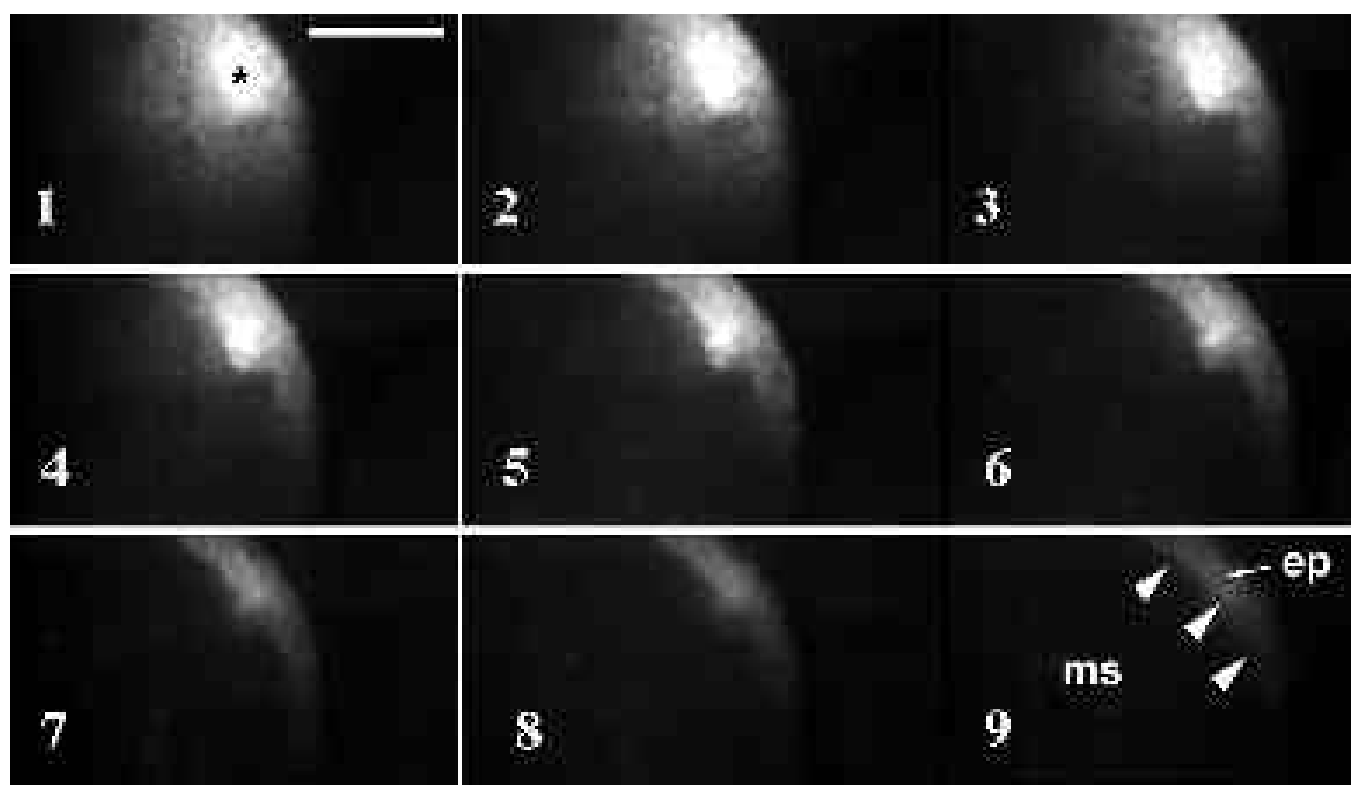

8

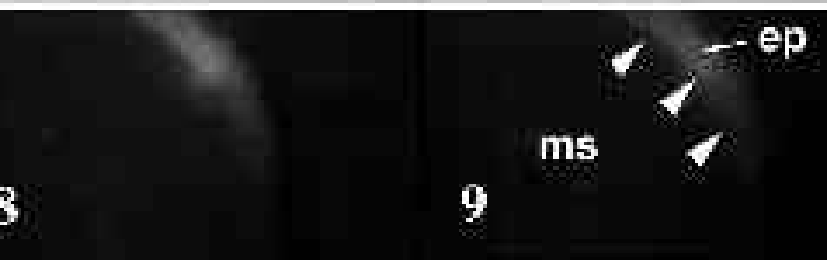

Fig. 8. Restricted dye distribution between epithelium and mesoderm following injection of an epithelial cell. Stage 34 chicken embryo skin. CLSM Zseries (9 images) of a preparation after injection into an epithelial cell of the feather bud. Panel 1 corresponds to the surface of the feather bud. Asterisk: injected cell. Panels 1-9 were taken in steps of $4 \mu \mathrm{m}$. Arrows in panel 9 point to the border between

epithelium (ep) and mesoderm (ms). Bar, $100 \mu \mathrm{m}$. Note that the dye from epithelial side or mesodermal side did not cross the mesodermal-epithelial junction. Bar, $100 \mu \mathrm{m}$.

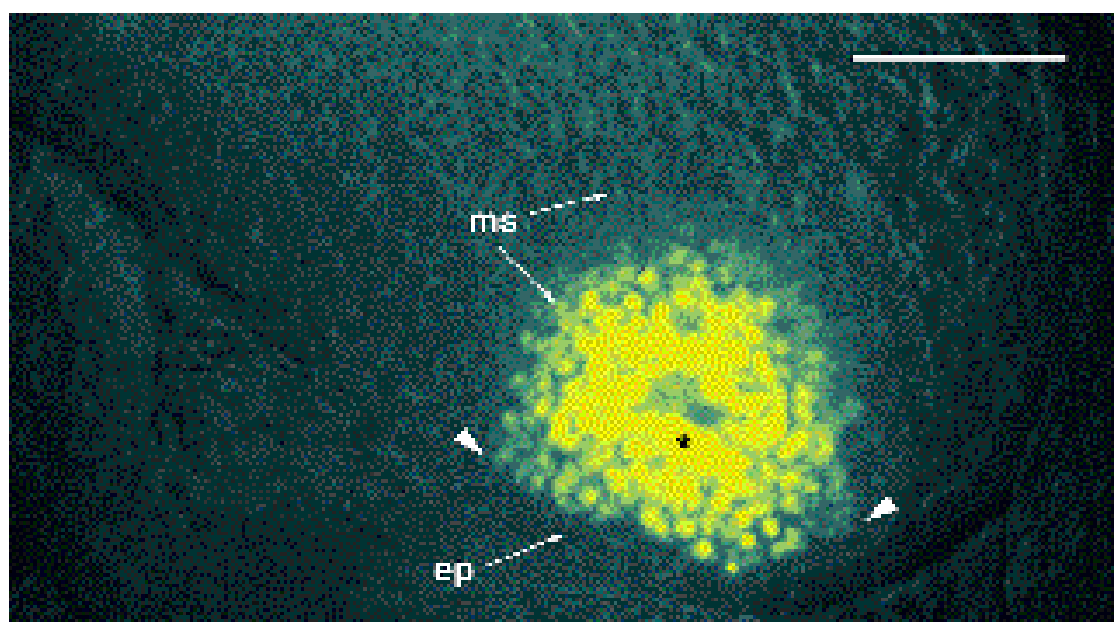

Fig. 9. Restricted dye distribution between epithelium and mesoderm following injection of a mesodermal cell. Colorized CLSM image of a preparation after the injection of Lucifer Yellow. Fluorescence (yellow) has been superimposed onto the phase image (grey). Note that the dye from mesodermal side did not cross the mesodermal-epithelial junction. Arrowheads point to the border between mesenchime and epithelium. Asterisk, injected cell. Bar, $100 \mu \mathrm{m}$

\section{DISCUSSION}

Morphogenesis during development is the result of complex cellular processes, which must, in part, be regulated by cellto-cell interactions. The interactions within and between mesodermal and ectodermal cells could be mediated through direct cell-to-cell contacts (eg., see Jessel and Melton, 1992; Edelman, 1992). The formation of skin appendages is a multiple stage event with continuous dialogues between epithelial and mesodermal cells, and is an excellent model to study cell interactions (Sawyer and Fallon, 1983; Chuong et al., 1993). In this report, we used intracellular iontophoresis of the fluorochrome Lucifer Yellow to demonstrate that cells of the developing chicken skin are well coupled by gap junctions. This approach for analyzing gap junctional communication has the advantage that it detects the presence of functional gap junction, capable of mediating the exchange of small signalling molecules between cells. The study revealed asymmetric patterns of dye coupling in developing skin, i.e. in the three-dimensional environment, the dye from the injected cell transfers to neighbors much faster in one direction than to others. This suggests that there are biases or preferential pathways of dye-spreading. We have identified four different patterns of dye coupling in this analysis of the developing chicken skin. The first pattern is the segregation between epithelia and mesoderm, the other three are the asymmetries in dye coupling within epithelia. Some of the borders between these populations coincide with known morphological borders (pattern 1 and asymmetry 2 described below), while some do not (asymmetrical pattern 3 and 4). The main patterns of dye coupling are summarized in Fig. 10.

\section{(1) No dye coupling between mesoderm and epithelium}

The results of our study suggest that, in skin development, 


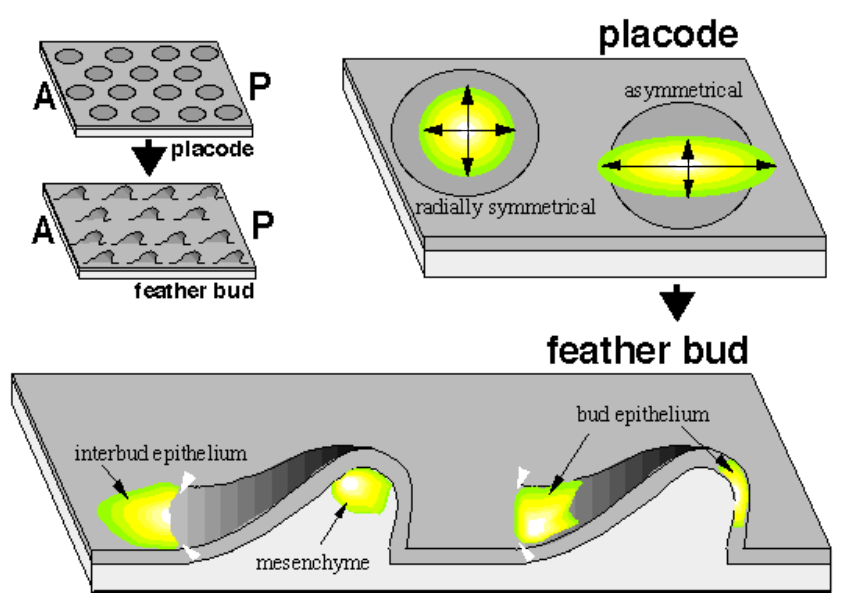

Fig. 10. Diagram summarizing the patterns of dye coupling in chicken developing skin. (Upper left) Low magnification of the development of skin from placode to feather bud; A, anterior side of the embryo; P, posterior side of the embryo. Note that all the feather buds are oriented in an A-P pattern. (Upper right) Dye coupling in a placode stage showing a radially symmetrical and an asymmetrical pattern. Arrows show the minor and major axis of the dye-coupled area. (Lower) Section through two feather buds, showing the patterns of dye coupling described. White arrowheads point to the communication boundary that separates the interbud and bud.

gap junctional communication is strong within a germ layer, but dye coupling is absent between two germ layers, suggesting that both mesoderm and epithelium form separated communication compartments. Functional communication assayed with dye coupling showed absence of communication between mesenchyme and epithelium. However, we can not exclude the possibility that we failed to detect communication at this stage because communication occurs at a very low level, in very localized sites, or only for a very short time interval. Since electrical coupling may occur in the absence of dye coupling, it is also possible that functional coupling across the dye restrictions described in this paper occurs beyond the detection limit of the dye-coupling assay.

Communication restrictions between and within mesoderm and ectoderm during development have been described in other systems (Kam et al., 1986; Kalimi and Lo, 1988; Serras et al., 1989, 1990). Communication restrictions between mesenchyme and epidermis have been associated with the differential expression of connexins (Laird et al., 1993). Similar to our findings, in the hair follicle differentiation, no dye coupling has been found between epithelial cells of the hair bulb and mesodermal cells of the dermal papillae (Kam and Hodgins, 1992); restrictions in dye coupling are absent in undifferentiated cells but appear between groups of cells during differentiation and growth (Kam and Hodgins, 1992). Connexins are differentially expressed in a specific spatiotemporal pattern during skin and hair follicle and sebaceous gland differentiation (Risek et al., 1992).

\section{(2) Partial restriction of dye coupling at the bud/interbud boundary}

Asymmetrical distribution of the dye was observed when the site of the injection was close to the border of the bud and interbud domains. The bud/interbud border acts as a boundary that restricts the passage of dye. This restriction appears during the progression of the placode to feather bud, when the epithelium and mesodermal core protrude from the placodes. Only occasional and slight exchange of Lucifer Yellow between interbud and bud cells can be found. This suggests that there is a significant but not absolute restriction of gap junctional communication between the bud and the interbud.

Different cell domains of the epithelia, such as bud and interbud, have been shown to express different expression patterns of adhesion molecules (Chuong and Edelman, 1985b; Richardson et al., 1987). The relationship among cell adhesion molecules, gap junctions and cell domains is particularly interesting. Inhibition of N-CAM-mediated adhesion in neuroectoderm leads to disruption of gap junctional communication and subsequent neural differentiation (Keane et al., 1988). E-cadherin (uvomorulin) is required for the formation and maintenance of gap junctions in epithelia (Gumbiner et al., 1988). During skin morphogenesis, antibodies to cadherins lead to the disruption of the hexagonal pattern of feather primordia (Gallin et al., 1986) and aborted hair growth (Takeichi, 1988), while antibodies to N-CAM lead to uneven segregation of feather buds (Jiang and Chuong, 1992). An attractive hypothesis is that adhesion molecules are used to define the border of cell domains, which will later be connected functionally via gap junctions. Thus, the reported disruptive effects of adhesion molecules antibodies (Jiang and Chuong, 1992) might be mediated, at least partially, by alterations in the normal pattern of gap junctional communication.

\section{(3) Preferential distribution of Lucifer Yellow along the anterior-posterior axis of the feather placode}

In the early placode stages of skin development, Lucifer Yellow shows some preference for passage along the A-P axis. The presence of asymmetries in the dye-coupling pattern suggests the existence of preferential pathways of communication in the skin, which may result in the asymmetrical transfer of small metabolites and potential signalling molecules.

The morphological asymmetry of feather buds does not become apparent until the feather buds grow out of the skin surface. Anterior-posterior differences in the distribution of a variety of molecules have been reported during feather bud development (Chuong and Edelman, 1985a; Chuong et al., 1990; Jiang and Chuong, 1992). Our results indicate that the A-P pathway of gap junctional communication occurs at the initiation of the placode stage and that its appearance is prior to either the molecular asymmetry or the morphological asymmetry. Therefore, it is tempting to speculate that the asymmetry in gap junction communication might bias the distribution of signals involved in setting up the A-P axis during the patterning of the skin.

\section{(4) Presence of dispersed epithelial cells that are not well coupled via gap junctions}

After injection of Lucifer Yellow in epithelial cells of the placodes, some pairs of cells appear to be isolated from the rest of epithelial cells. It is possible that the absence of 
coupling in this scattered population of cells is temporary and dependent upon the phase of the cell cycle, as found in other embryonic cells (Serras et al., 1990; Wan Su et al., 1990). For example, during the transition from the 8-cell stage to the 16-cell stage of the mouse embryos, gap junctional communication becomes reduced as the blastomeres enter mitosis and is resumed during the interphase of the 16cell stage (Goodall and Maro, 1986). It has been reported that dye coupling between dermal cells of the mouse becomes abruptly reduced in hyperproliferative conditions (Kam and Pitts, 1988, 1989). In transformed cells, restrictions in dye coupling appear at the borders that separate induced hyperpoliferative cells from the cells with normal mitotic activity (Mesnil and Yamasaki, 1988).

In summary, we observed that the cells in the developing skin are not uniformly coupled, instead there are asymmetrical patterns of dye coupling. During the development of the feather germs, the skin becomes subdivided into different tissue domains; our data show a parallel between these domains and the patterns of dye coupling. It remains uncertain whether the appearance of asymmetries in gap junctional communication is a cause or an effect of the subdivision of the skin in different cell domains. Some of the dye-coupling asymmetries (e.g. the anterior-posterior pattern dye transfer) appear before the cell domains defined by morphology or by molecular markers. This raises the intriguing possibility that asymmetries in gap junctional communication are primary and play a causal role in later patterning events. The distinct pattern formation process and accessibility to microinjection make feather development a model in which the roles of gap junctions in the asymmetric process of morphogenesis can be explored.

We thank Jean Paul Revel, Andrés Collazo and John Shih for their critical comments on the manuscript. This work was supported by a grant of the Netherlands Organization for Scientific Research (NWO) to F. S. and grants from NIH and NSF to C.-M. C.

\section{REFERENCES}

Allen, F., Tickle, C., and Warner, A. (1990). The role of gap junctions in patterning of the chick limb bud. Development 108, 623-634.

Brehm, P., Lechleiter, J., Smith, S., and Dunlap, K. (1989). Intercellular signaling as visualized by endogenous calcium-dependent bioluminiscence. Neuron 3, 191-198.

Chuong, C.-M., and Edelman, G. M. (1985a). Expression of cell adhesion molecules in embryonic induction. I. Morphogenesis of nestling feathers. J. Cell Biol. 101, 1009-1026.

Chuong, C.-M., and Edelman, G. M. (1985b). Expression of cell adhesion molecules in embryonic induction II. Morphogenesis of adult feathers. $J$. Cell Biol. 101, 1027-1043.

Chuong, C. M., Widelitz, R. B., and Jiang, T. X. (1993). Roles of adhesion molecules and homeoproteins in the phenotypic determination of skin appendages. J. Invest. Dermatol. In press.

Chuong, C.-M., Chen, H. M., Jiang, T. X., and Chia, J. (1991). Adhesion molecules in skin development: morphogenesis of feather and hair. Ann. NY Acad. Sci. 642, 263-280.

Chuong, C.-M., Ting, S. A., Widelitz, R. B., and Lee Y.-S. (1992). Mechanism of skin morphogenesis: II Retinoic acid modulates axis orientation and phenotipes of skin appendages. Development 115, 839852.

Chuong, C-M., Oliver, G., Ting, S., Jegalian, B., Chen, H. M., and De Robertis, E. M. (1990). Gradient of homeoproteins in developing feather buds. Development 110, 1021-1030.
Cornell-Bell, A. H., Finkbeiner, S. M., Cooper, M. S. and Smith, S. (1990). Glutamate induces calcium waves in cultured astrocytes: longrange glial signaling. Science 247, 470-473.

Crossin, K. L., Chuong, C.-M., and Edelman, G. M. (1985). Expression sequences of cell adhesion molecules. Proc. Natl. Acad. Sci. USA 82, 6942-6946.

Edelman, G. M. (1992). Morphoregulation. Dev. Dynamics 193, 2-10.

Fraser, S. E., Green, C. R., Bode, H. R., and Gilula, N. B. (1987). Selective disruption of gap junctional communication interferes with patterning process in Hydra. Science 237, 49-55.

Gallin, W. J., Chuong, C-M, Finkel, L. H., and Edelman, G. M. (1986). Antibodies to L-CAM perturb inductive interactions and alter feather pattern and structure. Proc. Natl. Acad. Sci. USA 83, 8235-8239.

Goodall, H. and Maro, B. (1986). Major loss of junctional coupling during mitosis in early mouse embryos. J. Cell Biol. 102, 568-575.

Gumbiner, B., Stevenson, B. and Grimaldi, A. (1988). The role of the cell adhesion molecule uvomorulin in the formation and maintenance of the epithelial junctional complex. J. Cell Biol. 107, 1575-1587.

Guthrie, S. C. and Gilula, N. B. (1989). Gap junctional communication in development. Trends Neurosci. 12, 12-15.

Hamburger, V. and Hamilton, H. L. (1951). A series of normal stages in the development of the chick embryo. J. Morphol. 88, 49-93.

Jessel, M. T., and Melton, D. A. (1992). Diffusible factors in vertebrate embryonic induction. Cell 68, 257-270.

Jiang, T. X., and Chuong, C. M. (1992). Mechanism of feather morphogenesis: I. Analyses with antibodies to adhesion molecules tenascin, N-CAM and integrin. Dev. Biol. 150, 82-98.

Kalimi, G. H., and Lo, C. W. (1988). Communication compartments in the gastrulating mouse embryo. J. Cell Biol. 107, 241-255

Kam, E., Melville, L., and Pitts, J. D. (1986). Patterns of junctional communication in skin. J. Invest. Dermatol. 87, 748-753.

Kam, E., and Pitts, J. D. (1988). Effects of the tumor promoter 12-Otetradecanoylphorbol-13-acetate on junctional communication in intact mouse skin: persistence of homologous communication and increase of epidermal-dermal coupling. Carcinogenesis 9, 1389-1394.

Kam, E., and Pitts, J. D. (1989). Tissue specific regulation of junctional communication in the skin of the mouse fetuses homozygous for the repeated epilation (Er) mutation. Development 107, 923-929.

Kam, E., and Hodgins, M. B. (1992). Communication compartments in hair follicles and their implication in differentiative control. Development 114, 383-393.

Keane, R. W., Mehta, P. P., Rose, B., Honig, L. S., Loewenstein, W. R., and Rutishauser, U. (1988). Neural differentiation, NCAM-mediated cell adhesion, and gap junctional communication in neuroectoderm. A study in vitro.J. Cell Biol. 106, 1307-1319

Laird, D. W., Yancey, S. B., Bugga, L., and Jean Paul Revel (1993). Connexin expression and gap junction communication compartments in the developing mouse limb. Dev. Dynamics (in press).

Lawrence, T., Beers, W. H., and Gilula, N. B. (1978). Transmission of hormonal stimulation by cell-to-cell communication. Nature 272, 501506.

Lee, S., Gilula, N. B., and Warner, A. E. (1987). Gap junctional communication and compaction during preimplantation stages of mouse development. Cell 51, 851-860.

Mauger, A., Demarchez, M., Herbage, D., Grimaud, J. A., Druguet, M., Hartmann, D. and Sengel, P. (1982). Immunofluorescent localization of collagen types I and III, and of fibronectin during feather morphogenesis in the chicken embryo. Dev. Biol. 94, 93-105.

Meinhardt, H. (1984). Models for pattern formation during development of higher organisms. In Pattern Formation (ed. G. M. Malacinski and S. V. Bryant), pp 47-72. New York: Macmillan.

Mesnil, M. and Yamasaki, H. (1988). Selective gap-junctional communication capacity of transformed and non-transformed rat liver epithelial cell lines. Carcinogenesis 9, 1499-1502.

Richardson, G., Crossin, K. L., Chuong, C.-M., and Edelman, G. M. (1987). Expression of cell adhesion molecules in embryonic induction: III. Development of the otic placode. Dev. Biol. 119, 217-230.

Risek, B., Klier, F. G., and Gilula, B. N. (1992). Multiple gap junction genes are utilized during rat skin and hair development. Development 116, 639-651.

Saez, J. C., Connor, J. A., Spray, D. C. and Bennett, M. V. L. (1989). Hepatocyte gap junctions are permeable to the second messenger, imositol 1,4,5-triphosphate, and to calcium ions. Proc. Natl. Acad. Sci. USA 86, 2708-2712. 
Sawyer, R. H., and Fallon, J. F. (eds.) (1983). Epithelial-mesenchymal Interactions in Development, pp.147-161. New York: Praeger Publishers.

Serras, F., Dictus, W. J. A. G., and Van den Biggelaar, J. A. M. (1990). Changes in junctional communication associated with cell cycle arrest and differentiation of trochoblasts in embryos of Patella vulgata. Dev. Biol. 137, 207-216.

Serras, F., Damen, P., Dictus, W. J. A. G., Notenboom, R. G. E. and Van den Biggelaar, J. A. M. (1989). Communication compartments in the ectoderm of embryos of Patella vulgata. Roux's Arch. Dev. Biol. 198, 191-200.

Stewart, W. W. (1978). Functional connections between cells as revealed by dye coupling with highly fluorescent naphthalimide tracer. Cell 14, 741-759.
Takeichi, M. (1988). The cadherins: cell-to-cell adhesion molecules controlling animal morphogenesis. Development 102, 639-655.

Wan Su, J., Tertoolen, L. G. J., de Laat, S. W., Hage, W. J., and Durston, A. J. (1990) Intercellular communication is cell cycle modulated during early Xenopus laevis development. J. Cell Biol. 110, 115-121.

Warner, A. E., and Gurdon, J. B. (1987). Functional gap junctions are not required for muscle gene activation by induction in Xenopus embryos. $J$. Cell Biol. 104, 557-564.

Warner, A. E., Guthrie, S. C., and Gilula, N. B. (1984). Antibodies to gap junctional protein selectively disrupt junctional communication in the early amphibian embryo. Nature 311, 127-131.

(Accepted 11 June 1993) 